\title{
Feasibility of Using Common Data Model for Orthopedic Research: Analysis of Risk Factors for Periprosthetic Joint Infection after Total Joint Arthroplasty
}

\section{Young Ju Chae}

Seoul National University College of Medicine

Jin Ho Shin

Seoul National University Bundang Hospital

Sung Jae Jung

Seoul National University Bundang Hospital

Hyun Sik Gong ( $\sim$ hsgong@snu.ac.kr)

Seoul National University College of Medicine https://orcid.org/0000-0003-4028-1559

\section{Research article}

Keywords: Total joint arthroplasty, Revision, Periprosthetic joint infection, Risk factors, Common data model

Posted Date: December 1st, 2020

DOl: https://doi.org/10.21203/rs.3.rs-116147/v1

License: (1) This work is licensed under a Creative Commons Attribution 4.0 International License. Read Full License 


\section{Abstract}

Background: Common data model (CDM) is a standardized data structure defined to efficiently use different sources in hospitals. A study using the CDM is scarce for orthopedic outcome researches due to the complexity of variables. We aimed to test the feasibility of applying CDM in the orthopedic field and analyzed risk factors for periprosthetic joint infection (PJI) after total joint arthroplasty (TJA) using CDM.

Methods: We undertook a retrospective cohort study of all primary and revision hip and knee TJAs at our institution from January 2003 to October 2017. We identified potential risk factors for PJI after TJAs in the literatures, which included preoperative demographic/social factors, previous medical history, intraoperative factors, laboratory results and others. The data sourced from EMR was extracted, transformed, and loaded into CDM.

Results: Variables such as demographic/social factors, medical history and laboratory results could be converted into CDM, but the other known risk factors could not. In total, 12,320 primary hip and knee TJAs and 120 revision arthroplasties were identified. Among them, 34 revisions were done because of PJI. Risk factors of PJI were hypertension and urinary tract infection after total hip arthroplasty, and age (70-79 years), male sex, anemia, steroid use, and urinary tract infection after total knee arthroplasty.

Conclusions: This study demonstrates that orthopedic outcome researches using CDM is feasible although data converting to CDM was possible for limited factors. Further data transforming technologies need to be developed to analyze more factors relevant to orthopedic area, such as intraoperative factors and imaging findings.

\section{Background}

Research using medical information has been actively carried out through the development of the information technology (IT). Commonly, electronic medical records (EMR) or administrative claims databases have been widely used for observational studies of clinical data. However, inconsistent data formats make large-scale clinical research collaboration between hospitals difficult and take a lot of time and effort. Thus, the need for standardization of EMR data is considered important in the medical field. The development of standard clinical information models is an attempt to tackle the storage and exchange of clinical data. Some researchers have shown that analyzing EMR data using standard-based methods is economical and improves efficiency [21, 25]. Common Data Model (CDM) allows for the systematic analysis of disparate observational databases. The concept is to transform different data into a standardized common data format by coding schemes and terminologies.

Total joint arthroplasty (TJA) is a commonly performed orthopedic procedure that can improve quality of life in patients with advanced arthritis. Over the past two decades, the number of TJAs has increased exponentially [7]. However, periprosthetic joint infection (PJI), which is the most serious complication of TJA, can result in severely limited joint function and increased mortality. Many studies have attempted to identify risk factors for PJI, which include rheumatoid arthritis, diabetes, renal disease, depression, hypercholesterolemia, anemia, urinary tract infection, hypertension, age, male, obesity, smoking, steroid use, blood transfusion, prolonged operative time, wound problem, and malnutrition $[1,2,4,6,8-10,15-17,20,24,26-28,30,34]$. However, only a few of them have considered multiple risk factors $[2,4,6,8,27,34]$. Furthermore, results obtained from different studies examining the same risk factor have reported conflicting results [29]. 
Although several studies have been performed for orthopedic outcome researches using EMR or administrative claims databases, studies using CDM is scarce due to the complexity of variables in the orthopedic field.

Therefore, we wanted to test the feasibility of applying CDM in the orthopedic research, especially for evaluation of risk factors of PJI. As such, the purposes of this study were, 1) to apply standard CDM methods and algorithms to an observational orthopedic research, and to identify problems in converting EMR parameters into CDM, and 2) to evaluate risk factors of PJI when analyzed by CDM.

\section{Methods}

\section{Patients}

We obtained approval from Institutional Review Board (IRB) for this retrospective review of medical records. We included patients who underwent primary TJAs (hip and knee) from January 2003 to October 2017 at our institution, which is a referral, training hospital located in an urban area in South Korea. We first identified cases of revision after TJA by using the International Statistical Classification of Diseases and Related Health Problems 10th Revision (ICD-10) diagnosis codes in EMR. The reasons for revision were periprosthetic joint infection (PJI), loosening, prosthesis failure, periprosthetic fracture, osteolysis, and dislocation. Then we identified cases of PJI from the revision cases and focused on the risk factors of PJI (Fig. 1). The patients with prior primary or revision surgery at outside hospitals were excluded. Staged revision procedures for infection were counted only once.

\section{Risk factors for PJI}

We searched for all possible risk factors for PJI in the literatures[2, 3, 13, 29, 34] and collected the following clinical data: preoperative demographic/social factors (age and sex), previous medical history (comorbidities and drug history), intraoperative factors (operative time, oxygenation, preparation, skin closure, and blood transfusion), laboratory results (albumin, cholesterol, blood cell counts, inflammatory markers, etc.) and others (admission days, observation duration, and venous thromboembolism prophylaxis). Among these data, we identified items that could be converted to CDM to test the feasibility. All clinical data abstracted were at the time of primary TJA.

\section{Conversion of EMR parameters to CDM}

The algorithm that EMR data converted to CDM is as follows; mapping EMR to standard concepts, extractiontransformation-loading (ETL) of patient data into CDM, and evaluation of the CDM-based results [11](Fig. 2). The coding system used for diagnosis in the EMR is an ICD-10 code, whereas the standard concept of CDM for diagnosis is based on the Systematized Nomenclature of Medicine Clinical Terms (SNOMED-CT) [31]. Although most codes was mapped to CDM through the SNOMED-CT, the standard concepts of CDM for drug exposure was based on the RxNorm from the US National Library of Medicine for medications [19]. However, all of codes in EMR were not corresponded to mapping in the CDM version available at the time of this research. Therefore, we conducted to find the corresponding CDM code with the mapped code, which was then re-grouped to obtain the desired value from the code in the CDM. To ensure minimal grouping errors and minimal information loss, four authors reviewed the concept mappings and achieved agreement by consensus.

To perform mapped patient data into CDM, extraction, transformation, and loading (ETL) process is required. We performed the ETL process on five tables. Five core tables are involved in our data loading: person [demographic characteristics], condition occurrence [medical history], measurement [laboratory results], procedure occurrence [procedures], and drug exposure [drug use] (Fig. 3). 
To load patient data into CDM, we developed the ETL scripts as a form of Standard Query Language (SQL) according to study design, and performed them as actual ETL process (Fig. 4).

\section{Statistical analysis}

For categorical variables, chi-squared and fisher's exact test were performed using PJI as a dependent variable and each parameter as an independent variable. For blood results two variables (low vs. high) were generated based on the reference ranges used by our hospital laboratory and analyzed as categorical variables. Continuous variables were analyzed by using t-tests and categorical variables by chi-square tests. We performed logistic regression analysis to identify risk factors associated with PJI. Odd ratios (OR) and 95\% confidence intervals (Cl) were calculated using $R$ package for Windows with the level of significance set at $P<0.05$. We also calculated adjusted OR using the propensity score matching for age and sex to reduce selection bias. We used Matchlt package to conduct propensity score matching with a ratio of one to five.

\section{Results}

\section{Patient characteristics}

A total of 12,320 primary TJAs (4,758 total hip arthroplasties (THAs) and 7,562 knee total knee arthroplasties (TKA)) were identified from January 2003 and October 2017. The most common cause was osteoarthritis (THA, 1040; TKA, 7305). Others cause included inflammatory arthritis, avascular necrosis, congenital dysplasia, fracture, ankylosis, dislocation, instability. There were 120 revision surgeries (1\%, 120/12,320) including 71 after THA (1.5\%) and 49 TKA (0.7\%). The most common causes for revision after THA were loosening (21 cases, $27.3 \%)$, followed by PJI (16 cases, 20.8\%), periprosthetic fracture (16 cases, 20.8\%), prosthesis failure (11 cases, $14.3 \%$ ), dislocation (10 cases, $13 \%$ ), and osteolysis (3 cases, 3.9\%). For TKA, loosening (28 cases, $52.8 \%$ ) was also the most common cause for revision, followed by PJI (18 cases, 34\%), osteolysis (3 cases, 5.7\%), prosthesis failure (3 cases, $5.7 \%$ ), and periprosthetic fracture (1 case, $1.9 \%$ ) (Table 1 ). 
Table 1

Causes of primary and revision total hip and knee arthroplasty

\begin{tabular}{|c|c|c|c|c|c|c|c|}
\hline \multicolumn{4}{|c|}{ Primary arthroplasty $(n=12320)$} & \multicolumn{4}{|c|}{ Revision arthroplasty $(n=120)$} \\
\hline Hip $(n=4758)$ & & Knee $(n=7562)$ & & Hip $(n=71)$ & & Knee $(n=49)$ & \\
\hline Diagnosis & $\begin{array}{l}\text { Number } \\
(\mathrm{n})\end{array}$ & Diagnosis & $\begin{array}{l}\text { Number } \\
\text { (n) }\end{array}$ & Diagnosis & $\begin{array}{l}\text { Number } \\
(\mathrm{n})\end{array}$ & Diagnosis & $\begin{array}{l}\text { Number } \\
(\mathrm{n})\end{array}$ \\
\hline AVN & $\begin{array}{l}1648 \\
(36.5 \%)\end{array}$ & OA & $\begin{array}{l}7305 \\
(92.8 \%)\end{array}$ & Loosening & $\begin{array}{l}21 \\
(27.3 \%)\end{array}$ & Loosening & $\begin{array}{l}28 \\
(52.8 \%)\end{array}$ \\
\hline Fracture & $\begin{array}{l}1063 \\
(23.5 \%)\end{array}$ & RA & $\begin{array}{l}366 \\
(4.7 \%)\end{array}$ & PJI & $\begin{array}{l}16 \\
(20.8 \%)\end{array}$ & PJI & $\begin{array}{l}18 \\
(34 \%)\end{array}$ \\
\hline OA & $\begin{array}{l}1040 \\
(23 \%)\end{array}$ & $\begin{array}{l}\text { Traumatic } \\
\text { OA }\end{array}$ & $\begin{array}{l}76 \\
(1 \%)\end{array}$ & $\begin{array}{l}\text { Periprosthetic } \\
\text { fracture }\end{array}$ & $\begin{array}{l}16 \\
(20.8 \%)\end{array}$ & Osteolysis & $\begin{array}{l}3 \\
(5.7 \%)\end{array}$ \\
\hline $\begin{array}{l}\text { Inflammatory } \\
\text { arthritis }\end{array}$ & $\begin{array}{l}186 \\
(4.1 \%)\end{array}$ & AVN & $\begin{array}{l}62 \\
(0.8 \%)\end{array}$ & $\begin{array}{l}\text { Prosthesis } \\
\text { failure }\end{array}$ & $\begin{array}{l}11 \\
(14.3 \%)\end{array}$ & $\begin{array}{l}\text { Prosthesis } \\
\text { failure }\end{array}$ & $\begin{array}{l}3 \\
(5.7 \%)\end{array}$ \\
\hline RA & $\begin{array}{l}177 \\
(3.9 \%)\end{array}$ & $\begin{array}{l}\text { Inflammatory } \\
\text { arthritis }\end{array}$ & $\begin{array}{l}35 \\
(0.5 \%)\end{array}$ & Dislocation & $\begin{array}{l}10 \\
(13 \%)\end{array}$ & $\begin{array}{l}\text { Periprosthetic } \\
\text { fracture }\end{array}$ & $\begin{array}{l}1 \\
(1.9 \%)\end{array}$ \\
\hline $\begin{array}{l}\text { Congenital } \\
\text { dysplasia }\end{array}$ & $\begin{array}{l}148 \\
(3.3 \%)\end{array}$ & Ankylosis & $\begin{array}{l}10 \\
(0.1 \%)\end{array}$ & Osteolysis & $\begin{array}{l}3 \\
(3.9 \%)\end{array}$ & & \\
\hline Dislocation & $\begin{array}{l}100 \\
(2.2 \%)\end{array}$ & Dislocation & $\begin{array}{l}7 \\
(0.08 \%)\end{array}$ & & & & \\
\hline Ankylosis & $\begin{array}{l}80 \\
(1.8 \%)\end{array}$ & Instability & $\begin{array}{l}6 \\
(0.07 \%)\end{array}$ & & & & \\
\hline $\begin{array}{l}\text { Traumatic } \\
\text { OA }\end{array}$ & $\begin{array}{l}41 \\
(1 \%)\end{array}$ & Fracture & $\begin{array}{l}3 \\
(0.03 \%)\end{array}$ & & & & \\
\hline $\begin{array}{l}\text { Traumatic } \\
\text { AVN }\end{array}$ & $\begin{array}{l}28 \\
(0.6 \%)\end{array}$ & & & & & & \\
\hline Instability & $\begin{array}{l}4 \\
(0.1 \%)\end{array}$ & & & & & & \\
\hline Gout & $\begin{array}{l}1 \\
(0.02 \%)\end{array}$ & & & & & & \\
\hline
\end{tabular}

\section{Conversion of EMR parameters to CDM}

EMR variables such as demographic/social factors (age, sex), previous medical history (comorbidities, drug history), laboratory results (albumin, cholesterol, blood cell counts, inflammatory markers, etc.) and admission days were converted into CDM. However, intraoperative factors (operative time, oxygenation, preparation, skin 
closure, and blood transfusion) and others (observation duration, and venous thromboembolism prophylaxis) could not be converted to CDM (Table 2).

Table 2

Conversion of EMR parameters into CDM

\begin{tabular}{|c|c|c|c|}
\hline Category & Parameter & $\begin{array}{l}\text { Conversion } \\
\text { to CDM } \\
\text { (Yes/No) }\end{array}$ & Obstacles to conversion \\
\hline \multirow{2}{*}{$\begin{array}{l}\text { Demographic } \\
\text { factors }\end{array}$} & Age & Yes & \\
\hline & Sex & Yes & \\
\hline \multirow{2}{*}{$\begin{array}{l}\text { Previous medical } \\
\text { history }\end{array}$} & Comorbidities & Yes & \\
\hline & Drug history & Yes & \\
\hline Laboratory results & & Yes & \\
\hline \multirow{5}{*}{$\begin{array}{l}\text { Intraoperative } \\
\text { factors }\end{array}$} & Operative time & No & No corresponding CDM code \\
\hline & Oxygenation & No & No corresponding CDM code \\
\hline & Preparation & No & $\begin{array}{l}\text { No mapping of terminology code in } \\
\text { EMR }\end{array}$ \\
\hline & Skin closure & No & No EMR data \\
\hline & Blood transfusion & No & No corresponding CDM code \\
\hline \multirow[t]{4}{*}{ Others } & Admission days & Yes & \\
\hline & Observation duration & No & No corresponding CDM code \\
\hline & $\begin{array}{l}\text { Venous } \\
\text { thromboembolism }\end{array}$ & No & $\begin{array}{l}\text { No mapping of terminology code in } \\
\text { EMR }\end{array}$ \\
\hline & prophylaxis & & \\
\hline
\end{tabular}

\section{Risk factors of PJI}

Among the variables that could be converted to CDM, hypertension (OR, 4.6; 95\% Cl, 1.7-12.7; Adjusted OR, 9; 95\% $\mathrm{Cl}, 2.7-30.6)$ and urinary tract infection (OR, 14.6; 95\% Cl, 3.2-66.3; Adjusted OR, N/A) were found to be associated with PJI after THA.

For TKA, age bracket of 70 to 79 years (OR, 5.4; 95\% Cl, 1.9-15.2), male (OR, 5.7; 95\% Cl, 2.1-15.2), anemia (OR, $12.2 ; 95 \% \mathrm{Cl}, 2.8-54.1)$, steroid use (OR, 4.4; $95 \% \mathrm{Cl}, 1.3-15.1)$, and urinary tract infection (OR, 13.7; $95 \% \mathrm{Cl}, 3.1-$ 60.7) were found to be associated with PJI. We identified that anemia, steroid use and UTI were equally significant 
factors after adjustment (Table 3, 4, Additional file 1). However, there was no evidence of any significant associations of PJI with laboratory results (Additional file 2).

Table 3

Demographic factors as risk factors of PJI

\begin{tabular}{|c|c|c|c|c|c|c|c|c|c|}
\hline \multirow[t]{2}{*}{ Category } & \multirow{2}{*}{$\begin{array}{l}\text { Risk } \\
\text { factor }\end{array}$} & \multicolumn{4}{|l|}{ Hip } & \multicolumn{4}{|l|}{ Knee } \\
\hline & & $\begin{array}{l}\text { Revision } \\
(n=16)\end{array}$ & $\begin{array}{l}\text { Non- } \\
\text { revision } \\
(n= \\
4687)\end{array}$ & $\begin{array}{l}\mathrm{P} \text { - } \\
\text { value }\end{array}$ & $\begin{array}{l}\text { Odds } \\
\text { Ratio } \\
(95 \% \mathrm{Cl})\end{array}$ & $\begin{array}{l}\text { Revision } \\
(n=18)\end{array}$ & $\begin{array}{l}\text { Non- } \\
\text { revision } \\
(\mathrm{n}= \\
7513)\end{array}$ & $\begin{array}{l}\text { P- } \\
\text { value }\end{array}$ & $\begin{array}{l}\text { Odds } \\
\text { Ratio } \\
(95 \% \mathrm{Cl})\end{array}$ \\
\hline \multirow{15}{*}{$\begin{array}{l}\text { Demogra- } \\
\text { phic } \\
\text { factors }\end{array}$} & $\begin{array}{l}\text { Mean } \\
\text { Age } \\
\text { (years) }\end{array}$ & 62.8 & 59.8 & & & 71.4 & 66.7 & & \\
\hline & Age & 2 & 18 & 0.384 & $1.6(0.4$ & 1 & 1 & 0.532 & 1.4 \\
\hline & $10-19$ & 2 & 160 & 1 & & 13 & 4 & 0.000 & $10.3)$ \\
\hline & $20-29$ & 4 & 411 & 0.287 & $\sim 4.8)$ & 3 & 25 & 0.002 & 5.4 \\
\hline & $30-39$ & 3 & 585 & 1 & $1.9(0.6$ & 1 & 310 & 1 & $15.2)$ \\
\hline & $40-49$ & 2 & 762 & 0.752 & & & 2439 & & 0.2 \\
\hline & $50-59$ & 3 & 775 & 0.732 & $\begin{array}{l}\text { } 3.4 \text { (U) } \\
\sim \text {. }\end{array}$ & & 3945 & & $0.6)$ \\
\hline & $60-69$ & & 1011 & & $0.6(0.1$ & & 780 & & \\
\hline & $70-79$ & & 805 & & & & 9 & & $3.8)$ \\
\hline & $80-89$ & & 156 & & $\sim 4.3)$ & & & & \\
\hline & $90-99$ & & 4 & & & & & & \\
\hline & $\begin{array}{l}100- \\
109\end{array}$ & & & & & & & & \\
\hline & $\begin{array}{l}110- \\
119\end{array}$ & & & & & & & & \\
\hline & $>120$ & & & & & & & & \\
\hline & $\begin{array}{l}\text { Male } \\
\text { sex }\end{array}$ & 9 & 2022 & 0.188 & $\begin{array}{l}2.0(0.7 \\
\sim 56)\end{array}$ & 6 & 608 & 0.002 & $\begin{array}{l}5.7 \\
(2.1 \sim \\
15.2)\end{array}$ \\
\hline
\end{tabular}


Table 4

Previous medical history as risk factors of PJI

\begin{tabular}{|c|c|c|c|c|c|c|c|c|c|}
\hline \multirow[t]{3}{*}{ Category } & \multirow{3}{*}{$\begin{array}{l}\text { Risk } \\
\text { factor }\end{array}$} & \multicolumn{4}{|c|}{ Adjusted hip group } & \multicolumn{4}{|c|}{ Adjusted knee group } \\
\hline & & $\begin{array}{l}\text { Revision } \\
(\mathrm{n}=16)\end{array}$ & $\begin{array}{l}\text { Non- } \\
\text { revision }\end{array}$ & $\begin{array}{l}\text { P- } \\
\text { value }\end{array}$ & $\begin{array}{l}\text { Odds } \\
\text { Ratio }\end{array}$ & $\begin{array}{l}\text { Revision } \\
(\mathrm{n}=18)\end{array}$ & $\begin{array}{l}\text { Non- } \\
\text { revision }\end{array}$ & $\begin{array}{l}\text { P- } \\
\text { value }\end{array}$ & $\begin{array}{l}\text { Odds } \\
\text { Ratio }\end{array}$ \\
\hline & & & $(n=80)$ & & $(95 \% \mathrm{Cl})$ & & $(n=90)$ & & $(95 \% \mathrm{Cl}$ \\
\hline \multirow{5}{*}{$\begin{array}{l}\text { Previous } \\
\text { medical } \\
\text { history }\end{array}$} & HTN & 8 & 8 & 0.0006 & 9 & 9 & 30 & 0.1789 & 2 \\
\hline & & & & & $\begin{array}{l}(2.7 \sim \\
30.6)\end{array}$ & & & & $\begin{array}{l}(0.7 \sim ~ \\
5.6)\end{array}$ \\
\hline & Anemia & 1 & 0 & & & 2 & 0 & 0.0264 & NA \\
\hline & $\begin{array}{l}\text { Steroid } \\
\text { use }\end{array}$ & & 0 & & & 3 & 0 & 0.0039 & NA \\
\hline & UTI & 2 & 0 & 0.0263 & NA & 2 & 0 & 0.0264 & NA \\
\hline
\end{tabular}

Boldface indicates statistical significance.

Detailed information on the Table 4 is given in Additional file 1.

\section{Discussion}

\section{Rationale, Summary, Significance}

We aimed to test the feasibility of applying common data model (CDM) in the orthopedic field and analyzed risk factors for periprosthetic joint infection (PJI) after total joint arthroplasty. Variables such as demographic/social factors, medical history, laboratory results and admission days could be converted into CDM, but the others such as intraoperative factors, observation duration, and venous thromboembolism prophylaxis could not be converted to CDM. When analyzed by using CDM, we found that hypertension and urinary tract infection were risk factors of PJI after THA, and age bracket of 70 to 79 years, male, anemia, steroid use and urinary tract infection were risk factors of PJI after TKA. This study demonstrates orthopedic researches using CDM is feasible although data converting to CDM was possible for limited factors.

\section{Conversion of EMR parameters to CDM}

The CDM is designed to include all observational data derived from the EMR to support the generation of reliable evidence $[11,25]$. It is important to obtain what we want from the study by properly designing the algorithm with the parameters currently available in the CDM. Creating mappings the variable EMR data into the target CDM concepts is also crucial to improve patient data standardization [14,22]. Thus, in previous studies, cohort studies have been mainly focused on the pharmacoepidemiological research as treatment of diseases and epidemiological analysis of deaths from certain diseases [11, 12, 19, 23, 32, 33]. In our case, we focused on parameters related to risk factors for PJI after TJA and constructed the algorithm directly using SQL, not through 
programs already created within the CDM, to achieve the desired results in our study. Of course, the code mapping process was not easy. Four authors reviewed the code mapping, but because of incomplete concepts matching and difference between the coding systems, a little information loss was inevitable. In addition, the data in EMR are typically expressed in non-standard terms, and the textual variable values are often in free-style using different local expressions, we could not standardize these terms and the textual values into standard concepts in this study.

The main advantages of research using CDM is that such studies can be conducted on a larger scale, against lower costs, and within shorter time frames than traditional studies [5]. Also, it protects the privacy and security of patients in research because not the information of a certain patient but the information of a certain result is used in CDM tool [25]. In our study, to maintain patient confidentiality privacy and security, the original patient identifications were removed when the patient data were converted to the CDM. The CDM is also an important part of multi-organization collaborative research $[19,22]$. Because each hospital has a different structure in patient information, it is necessary to cooperate with multiple hospitals to provide information for standardization of patient information through CDM tool. However, differences in data structures and coding system are still major barriers to standardize data in CDM tool [31].

\section{Risk factors of PJI}

In this study, hypertension was identified as a significant risk factor of PJI after THA, which is concurrent with some studies $[1,2,6,30]$. The studies demonstrated that hypertension is associated with delayed wound healing following TJA.

Urinary tract infection (UTI) was a significant risk factor of PJI after both THA and TKA in this study. Usually, UTI is more common in women than in men and the reported prevalence of UTI in women undergoing primary TJA ranges from $5.1-36 \%[4,6,9,26]$. Therefore, symptomatic UTI should be treated before proceeding TJA.

We found an association between age and risk of revision, which is consistent with previous findings [5, 7, 1721]. Although older patient age would seem to coincide with poorer nutritional status and thus elevated infection risk, some studies reported an increased risk of revision for relatively younger patients $[7,17,18,22]$.

This study found that a male sex was a significant risk factor of PJI after TKA, which coincides with some studies $[3,6,15,27,29]$. A study suggested that men can get a greater degree of surgical trauma and tissue necrosis than in women [27]. Also, men have a more active life-style than women after TJA. Therefore, differences in exercise volume can cause overuse differences after TJA, which may result in revision surgery.

In this study, preoperative anemia was also associated with risk factors of PJI after TKA. Anemia is usually associated with a patient's poor nutritional status. Previous literatures have shown that primary TJA patients who have preoperative anemia are more likely to receive blood transfusions, which are associated with an increased risk of postoperative infection $[2,4,8-10]$. Therefore, patients should be preoperatively evaluated for causes of anemia, such as iron deficiency, and considered for recombinant human erythropoietin treatment in order to decrease the risk of PJI $[8,10]$.

We also found steroid use as a risk factor of PJI after TKA, which is consistent with previous literatures $[2,6,18$, 28]. The association between steroid use and PJI is likely to be mediated at least in part by impaired wound healing due to the anti-inflammatory and immuno-suppressive effects of steroids [20]. In addition, steroid use can 
cause problems of calcium and vitamin D metabolism, zinc deficiency, and most importantly an accelerated bone mineral loss [16].

\section{Limitations of study}

There are several limitations to our study that must be noted. First, although the study objective was to utilize a CDM to identify risk factors of PJI after TJA, we couldn't analyze all of them that have been reported in the literature. We couldn't use non-matching EMR code in CDM. In our further study, we will continue improving the scalability of the converting variable data to CDM. Further data transforming technologies need to be developed to analyze more factors relevant to orthopedic area, such as intraoperative factors and imaging findings. Second, the subjects were from a single institution and our methodology has not been tested with other uses. The research of CDM designed for one use might lack credibility in terms of methodology. Therefore, the generalizability still needs to be confirmed. We will conduct subsequent research to use multi-center data for large-scale analysis and further validate our methods.

\section{Conclusions}

This study presents an approach to achieve semantic standardization among different clinical data sources by using CDM in the orthopedic field. Although data converting to CDM was possible for limited factors, we could propose reusable data transforming method. Therefore, it may differ for other uses and associated data element sets, but we consider that the methodology reported here can be applied to other researches in the orthopedic field.

\section{Abbreviations}

EMR: Electronic medical records; CDM: Common data model; TJA: Total joint arthroplasty; THA: Total hip arthroplasty; TKA: Total knee arthroplasty; PJI: Periprosthetic joint infection; ETL: Extraction-TransformationLoading; SNOMED-CT: Systematized Nomenclature of Medicine Clinical Terms; SQL: Standard Query Language.

\section{Declarations}

\section{Acknowledgments}

We thank for the big data center in our hospital for their support, without which the present study could not have been completed.

\section{Funding}

This study was supported by the Seoul National University Bundang Hospital Research Fund.

\section{Availability of data and materials}

All relevant data are included in this manuscript. Additional data may be requested by contacting the corresponding author.

\section{Authors' contributions}


YJC, HSG, SJJ participated in the design of the study. YJC, JHS measured the data. YJC, SJJ, JHS were responsible for the statistical analysis of the study. All authors contributed to the writing of the manuscript.

\section{Competing interests}

The authors declare that they have no competing interests.

\section{Consent for publication}

Not applicable.

\section{Ethics approval and consent to participate}

This study was approved by the Institutional Review Board of the Seoul National University Bundang Hospital.

\section{References}

1. Ahmed AA, Mooar PA, Kleiner M, et al. Hypertensive patients show delayed wound healing following total hip arthroplasty. PLoS One. 2011;6:e23224.

2. Almustafa MA, Ewen AM, Deakin AH, et al. Risk Factors for Surgical Site Infection Following Lower Limb Arthroplasty: A Retrospective Cohort Analysis of 3932 Lower Limb Arthroplasty Procedures in a High Volume Arthroplasty Unit. J Arthroplasty. 2018;33:1861-1867.

3. Bottle A, Parikh S, Aylin P, et al. Risk factors for early revision after total hip and knee arthroplasty: National observational study from a surgeon and population perspective. PLoS One. 2019;14:e0214855.

4. Bozic KJ, Lau E, Kurtz S, et al. Patient-related risk factors for periprosthetic joint infection and postoperative mortality following total hip arthroplasty in Medicare patients. J Bone Joint Surg Am. 2012;94:794-800.

5. Carey DJ, Fetterolf SN, Davis FD, et al. The Geisinger MyCode community health initiative: an electronic health record-linked biobank for precision medicine research. Genet Med. 2016;18:906-913.

6. Chen J, Cui Y, Li X, et al. Risk factors for deep infection after total knee arthroplasty: a meta-analysis. Arch Orthop Trauma Surg. 2013;133:675-687.

7. Edwards $C$, Counsell A, Boulton $C$, et al. Early infection after hip fracture surgery: risk factors, costs and outcome. J Bone Joint Surg Br. 2008;90:770-777.

8. Eka A, Chen AF. Patient-related medical risk factors for periprosthetic joint infection of the hip and knee. Ann Transl Med. 2015;3:233.

9. Friedman R, Homering M, Holberg G, et al. Allogeneic blood transfusions and postoperative infections after total hip or knee arthroplasty. J Bone Joint Surg Am. 2014;96:272-278.

10. Greenky M, Gandhi K, Pulido L, et al. Preoperative anemia in total joint arthroplasty: is it associated with periprosthetic joint infection? Clin Orthop Relat Res. 2012;470:2695-2701.

11. Hong N, Zhang N, Wu H, et al. Preliminary exploration of survival analysis using the OHDSI common data model: a case study of intrahepatic cholangiocarcinoma. BMC Med Inform Decis Mak. 2018;18:116.

12. Hripcsak G, Ryan PB, Duke JD, et al. Characterizing treatment pathways at scale using the OHDSI network. Proc Natl Acad Sci U S A. 2016;113:7329-7336. 
13. Jasper LL, Jones CA, Mollins J, et al. Risk factors for revision of total knee arthroplasty: a scoping review. BMC Musculoskelet Disord. 2016;17:182.

14. Jiang G, Kiefer R, Prud'hommeaux E, et al. Building Interoperable FHIR-Based Vocabulary Mapping Services: A Case Study of OHDSI Vocabularies and Mappings. Stud Health Technol Inform. 2017;245:1327.

15. Johnsen SP, Sorensen HT, Lucht U, et al. Patient-related predictors of implant failure after primary total hip replacement in the initial, short- and long-terms. A nationwide Danish follow-up study including 36,984 patients. J Bone Joint Surg Br. 2006;88:1303-1308.

16. Kamal R, Bansal SC, Khandelwal N, et al. Moderate zinc supplementation during prolonged steroid therapy exacerbates bone loss in rats. Biol Trace Elem Res. 2014;160:383-391.

17. Katz JN WE, Guadagnoli E, Liang MH, et al. Differencesbetween men and women undergoing major orthopedic surgery for degenerative arthritis. Arthritis \& Rheumatism. 1994;37.

18. Kunutsor SK, Whitehouse MR, Blom AW, et al. Patient-Related Risk Factors for Periprosthetic Joint Infection after Total Joint Arthroplasty: A Systematic Review and Meta-Analysis. PLoS One. 2016;11:e0150866.

19. Lai EC, Ryan P, Zhang Y, et al. Applying a common data model to Asian databases for multinational pharmacoepidemiologic studies: opportunities and challenges. Clin Epidemiol. 2018;10:875-885.

20. Lee DM, Weinblatt ME. Rheumatoid arthritis. Lancet. 2001;358:903-911.

21. Martin-Sanchez FJ, Aguiar-Pulido V, Lopez-Campos GH, et al. Secondary Use and Analysis of Big Data Collected for Patient Care. Yearb Med Inform. 2017;26:28-37.

22. Overhage JM, Ryan PB, Reich CG, et al. Validation of a common data model for active safety surveillance research. J Am Med Inform Assoc. 2012;19:54-60.

23. Panaccio MP, Cummins G, Wentworth C, et al. A common data model to assess cardiovascular hospitalization and mortality in atrial fibrillation patients using administrative claims and medical records. Clin Epidemiol. 2015;7:77-90.

24. Park CH, Lee YK, Koo KH. Lower Urinary Tract Infection and Periprosthetic Joint Infection after Elective Primary Total Hip Arthroplasty. Hip Pelvis. 2017;29:30-34.

25. Park RW. A clinical research strategy using longitudinal observational data in the post-electronic health records era. Journal of the Korean Medical Association. 2012;55.

26. Parvizi J, Koo KH. Should a Urinary Tract Infection Be Treated before a Total Joint Arthroplasty? Hip Pelvis. 2019;31:1-3.

27. Pedersen AB, Svendsson JE, Johnsen SP, et al. Risk factors for revision due to infection after primary total hip arthroplasty. A population-based study of 80,756 primary procedures in the Danish Hip Arthroplasty Registry. Acta Orthop. 2010;81:542-547.

28. Peel TN, Dowsey MM, Daffy JR, et al. Risk factors for prosthetic hip and knee infections according to arthroplasty site. J Hosp Infect. 2011;79:129-133.

29. Prokopetz JJ, Losina E, Bliss RL, et al. Risk factors for revision of primary total hip arthroplasty: a systematic review. BMC Musculoskelet Disord. 2012;13:251.

30. Saleh K, Olson M, Resig S, et al. Predictors of wound infection in hip and knee joint replacement: results from a 20 year surveillance program. J Orthop Res. 2002;20:506-515.

31. Yoon D, Ahn EK, Park MY, et al. Conversion and Data Quality Assessment of Electronic Health Record Data at a Korean Tertiary Teaching Hospital to a Common Data Model for Distributed Network Research. Healthc

Page $12 / 15$ 
Inform Res. 2016;22:54-58.

32. Zhang X, Wang L, Miao S, et al. Analysis of treatment pathways for three chronic diseases using OMOP CDM. J Med Syst. 2018;42:260.

33. Zhou X, Murugesan S, Bhullar H, et al. An evaluation of the THIN database in the OMOP Common Data Model for active drug safety surveillance. Drug Saf. 2013;36:119-134.

34. Zhu Y, Zhang F, Chen W, et al. Risk factors for periprosthetic joint infection after total joint arthroplasty: a systematic review and meta-analysis. J Hosp Infect. 2015;89:82-89.

\section{Figures}

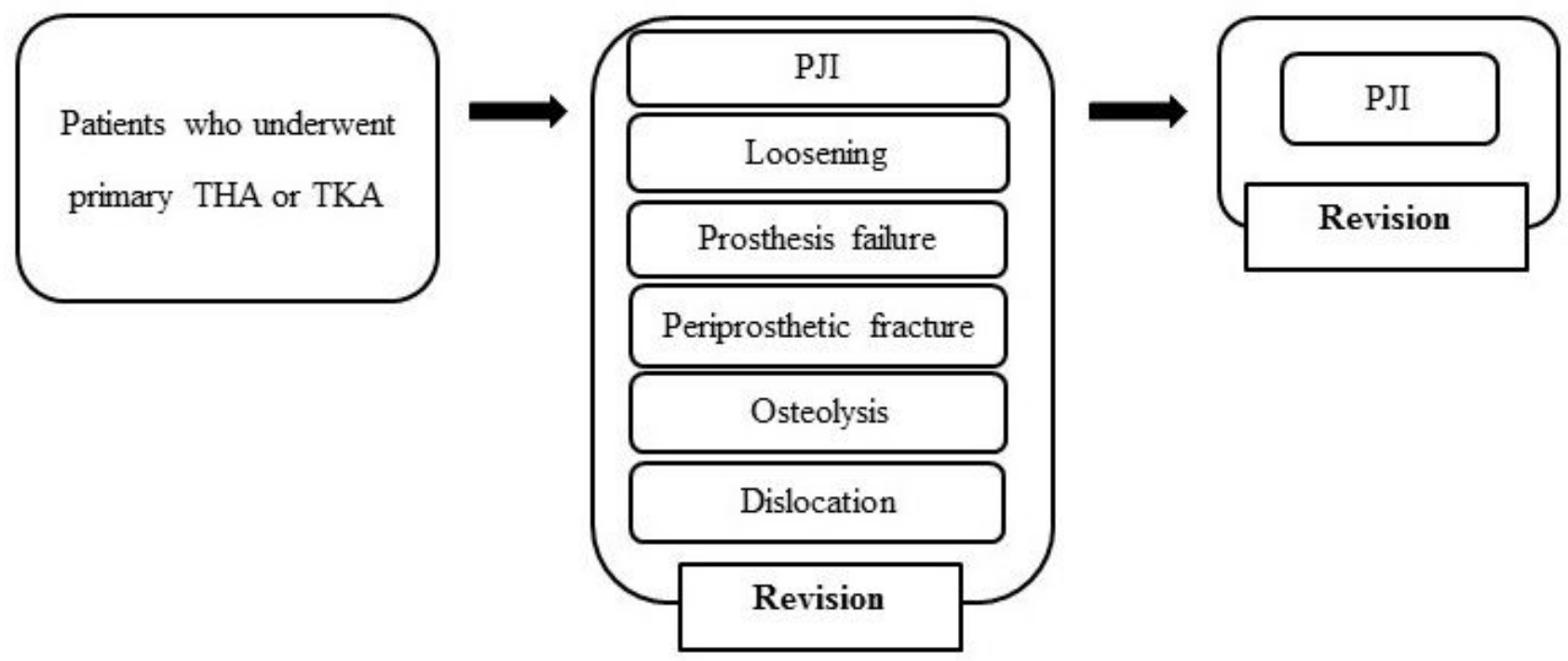

Figure 1

The patient selection flow chart.

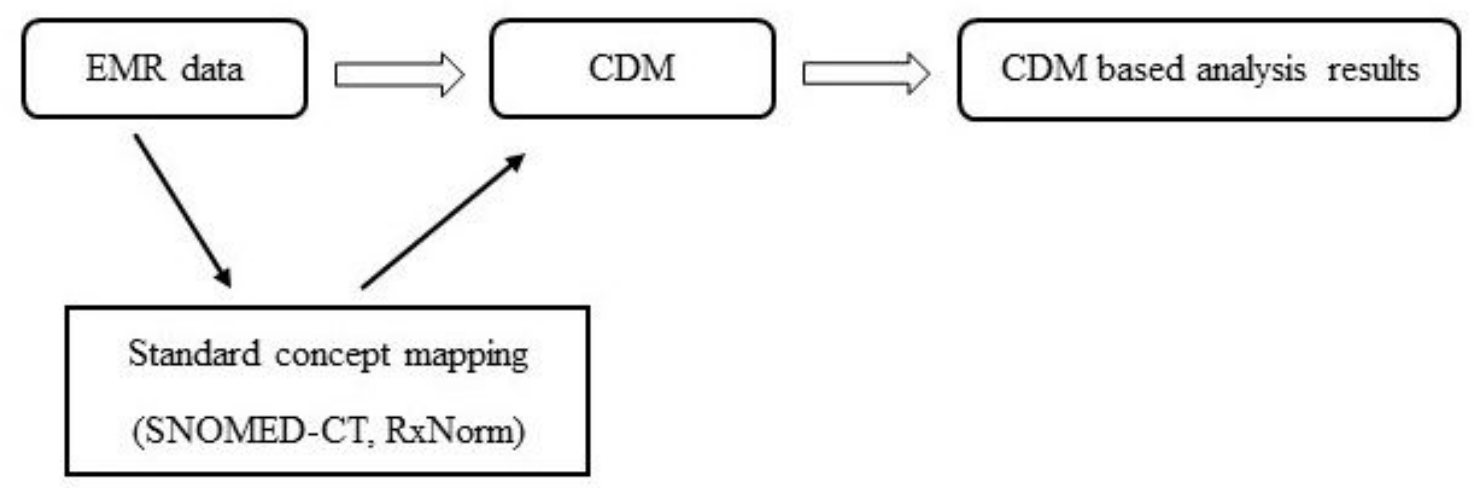

Figure 2 


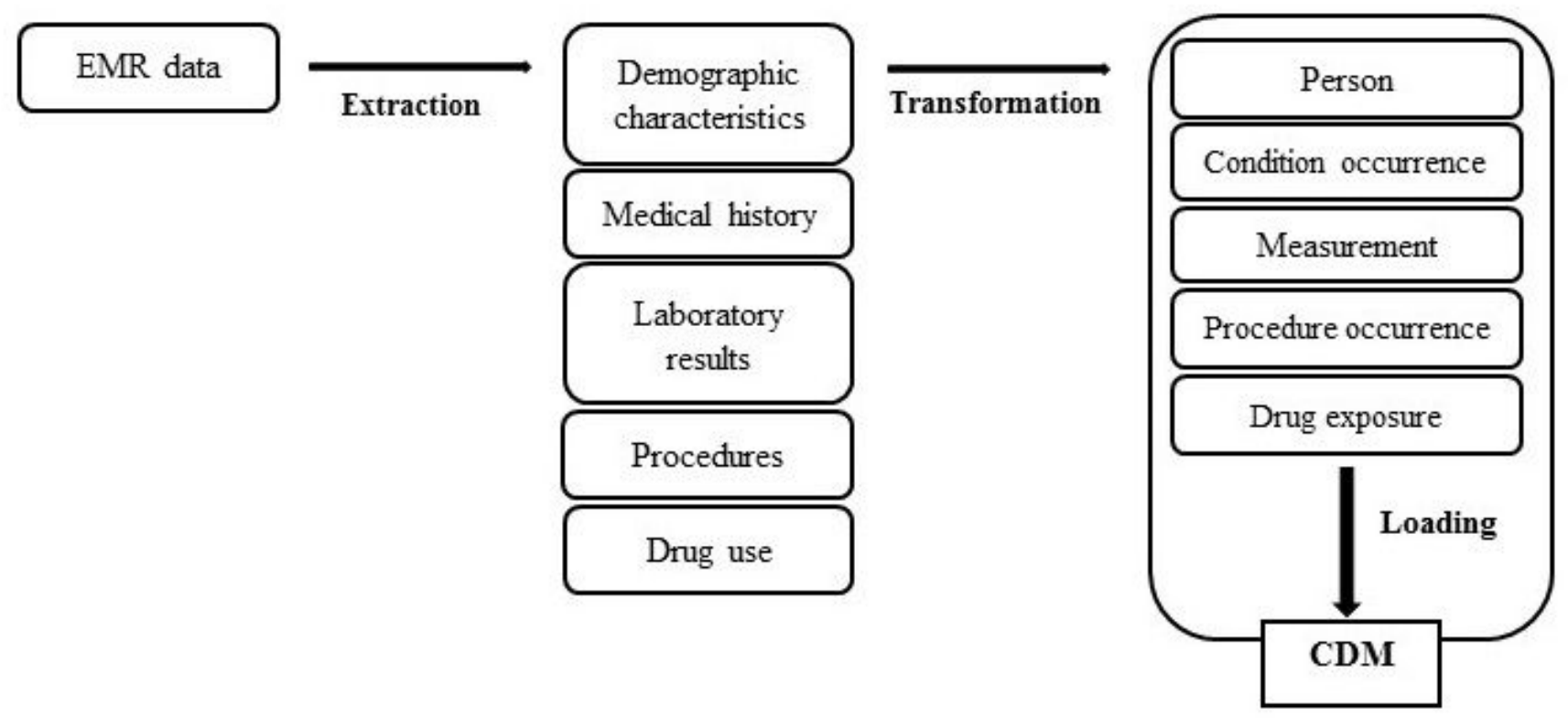

\section{Figure 3}

Extraction, Transformation, and Loading (ETL) process.

SBLBCT PROCEDURE_OCCURRENCE_ID, PERSON_ID,

PROCEDURE_CONCEPT_ID, PROCEDURE_DATE,

PROCEDURE_DATETIME, PROCEDURE_SOURCE_VALUE,

MIN (REVISED_YN) AS REVISED_YN,

MTN(HTN) AS HTN, MTN(RA) AS RA, MIN(Liver) AS Liver, MTH(Anemia) AS Anemia,

UIN(HYperchol) AS Hyperchol, UIN(Depression) AS Depression, UMN(Coagulation) AS Coagulation,

MIN (Heart) AS Heart, MNN(Previous) AS Previous, UIN(DM) AS DM,

MII (Rena1) AS Renal, MIN (Pulmonary) AS Pulmonary, MIN(FSI_PROC_DATE) FSI_PROC_DATE

FROM ( SELBCT A.*

, LBAD (REV_GB, 1) OVER (PARTITION BY A.PERSON_ID, NM ORDER BY A. PROCEDURE_DATETIME ASC) LEAD_REV_GB

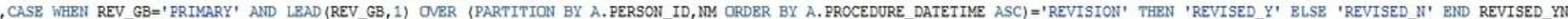

,CASE WHEN DIS_CLS_CD='HTN' ARID CONDITION_START_DATE>=FST_PROC_DATE THEN CONDITION_START_DATE BND AS HTM

, CASE WHEN DIS_CLS_CD='RA' AND CONDITION_START_DATE $>=F S T$ PROC_DATE THEN CONDITION_START_DATE END AS RA

,CASB WHEN DIS_CLS_CD='Liver' AND CONDITION_START_DATE>=FST_PROC_DATE THEN CONDITION_START_DATE BND AS LIVEr

,CASB WHEN DIS_CLS_CD='Anemia' AND COMDITION_START_DATE $>=F S T$ PROC_DATE THEN CONDITION_START_DATE BND AS Anemia

,CASE WHEN DIS_CLS_CD='Hypercho1' AND CONDITION_START_DATE>=FST_PROC_DATE THEN CONDITION_START_DATE RND AS HYperchol

'CASB WHEN DIS_CLS_CD='Depression' ARD COMDITION_STARI_DATE>=FST_PROC_DATE THEN CONDITION_START_DATE BID AS Depression

,CASE WHBN DIS_CLS_CD='Coagulation' AND CONDITION_START_DATE $>=F S T$ PROC_DATE THEN CONDITION_START_DATE BND AS COagulation

, CASB WHEN DIS_CLS_CD='Heart' AND CONDITION_START_DATE $>=F S T$ PROC_DATE THBN CONDITION_START_DATE END AS Heart

'CASB WHEN DIS_CLS_CD='Previous' AATD CONDITION_START_DATE $>=F S T$ PROC_DATE THEN CONDITION_START_DATE BND AS PreviOus

,CASE WHEN DIS_CLS_CD='DM' AND CONDITION_START_DATE>=FST_PROC_DATE THEN CONDITION_START_DATE BND AS DM

'CASE WHEN DIS_CLS_CD='Renal' AND COMDITION_START_DATE>=FST_PROC_DATE THEN CONDITION_START_DATE BND AS RenaI

,CASE WHEN DIS_CLS_CD='Pulmonary' ARID CONDITION_START_DATE>=FST_PROC_DATE THEN CONDITION_START_DATE BND AS FU1monary , FST_PROC_DATE

FROM (select a.*, 'REVISION' REV_GB from PROCEDURE_OCCURRENCE_REV a UNIOAT ALL

select a.*,'PRIMARY' REV_GB from PROCEDURE_OCCURRENCE_PRI a) A

LBET OUTER JOIN (select a.*

ROW_NUMBER() OVER (PARTITION BY PERSON_ID, DIS_CLS_CD ORDBR BY CONDITION_START_DATE ASC) RI

from CONDITION_OCCURRENCE_OSSTUDY a) B ON A.PERSON_ID $=B$. PERSON_ID ARD B.RN=

LEFT OUTER JOIN (select PERSON_ID, MIN(PROCEDURE_DATE) FST_PROC_DATE

From PROCEDURE_OCCURRENCE_PRI a

WHERE REV_GB=' PRIMARY' ,

group by PERSON_ID) $c$ ON A.PERSON_ID $=C$.PERSON_ID

GROUP BY PROCEDURE_OCCURRENCE_ID

,PERSON_ID

, PROCEDURE_CONCEPT_ID

,PROCEDURE_DATE

, PROCEDURE_DATETTME

, PROCEDURE_SOURCE_VALUE; 
ETL scripts as a form of Standard Query Language (SQL).

\section{Supplementary Files}

This is a list of supplementary files associated with this preprint. Click to download.

- Additionalfile1..docx

- Additionalfile2..docx 